\title{
Praktikalitas Materi Ajar Basic English Grammar Berbasis Multimedia pada Tingkat Perguruan Tinggi
}

\author{
Yuli Tiarina, Hermawati Syarif, Jufrizal, \& Yenni Rozimela \\ Program Pasca Sarjana, Universitas Negeri Padang \\ yulitriana@yahoo.co.id
}

\begin{abstract}
How to cite (in APA Style): Tiarina, Y., Syarif, H., Jufrizal., \& Rozimela, Y. (2019). Praktikalitas materi ajar basic english grammar berbasis multimedia pada tingkat perguruan tinggi. Jurnal Pendidikan Bahasa dan Sastra, 19(1), 61-71, doi: 10.17509/bs_jpbsp.v19i1.20759.
\end{abstract}

Article History: Received (24 January 2019); Revised (18 March 2019); Accepted (1 April 2019) Journal homepage: http://ejournal.upi.edu./index.php/BS_JPBSP

\begin{abstract}
Abstrak: Penelitian ini bertujuan untuk menemukan praktikalitas materi ajar Basic English Grammar Berbasis Multimedia Interaktif yang telah dikembangkan dan dapat diakses melalui http://thetiarina.com/e-tiarina/. Metode yang digunakan yaitu kuantitatif dengan melibatkan 3 orang mahasiswa untuk uji individu dan 27 orang mahasiswa untuk uji kelompok kecil. Temuan penelitian ini adalah (1) berdasarkan uji individu, kualitas desain pembelajaran dan tampilan visual Materi Ajar Basic Grammar tergolong baik (85,47 dan 83,33, dan; (2) berdasarkan uji kelompok kecil, kualitas desain pembelajaran dan tampilan visual draft Materi Ajar Basic Grammar juga tergolong baik $(84,26$ dan 87,85$)$, materi ajar ini mudah digunakan $(81,64)$ dan organisasi materi ajar ini mudah dipahami $(80,35)$.
\end{abstract}

Kata kunci: materi ajar; multimedia interaktif; praktikalitas

\section{The Practicality of Basic English Grammar Teaching Material Based on Interactive Multimedia in University Level}

\begin{abstract}
This article aims to find out the practicalities of Basic Multimedia Grammar Based Interactive Multimedia teaching material that has been developed and can be accessed through http://thetiarina.com/e-tiarina/. This research is a quantitative study involving 3 students for individual testing and 27 students for small group testing. The findings of this study are 1) Based on individual tests, the quality of learning design and visual appearance of Basic Grammar Teaching Materials is good (85.47 and 83.33; and 2) Based on small group tests, the quality of learning design and visual display of Basic Grammar Teaching Materials also relatively good (84.26 and 87.85), this teaching material is easy to use $(81,64)$ and the organization of teaching material is easy to understand $(80,35)$.
\end{abstract}

Keywords: teaching material; interactive multimedia; practicality 


\section{PENDAHULUAN}

Perkembangan mahasiswa sangat dipengaruhi oleh era atau zaman pada saat mereka hidup. Mahasiswa pada zaman ini adalah mahasiswa abad 21 yaitu mahasiswa yang hidup pada era informasi dan teknologi. Mahasiswa zaman ini adalah mahasiswa yang banyak menghabiskan waktunya untuk menggunakan internet. Mahasiswa di Cina menghabiskan waktunya 1 sampai dengan 5 jam mengakses internet untuk keperluan akademik atau lainnya (Li, 2012). Temuan serupa juga terjadi di Oman dan India. Mahasiswa di Oman dan India menghabiskan waktunya untuk mengakses internet lebih dari 4 jam per hari. Ditemukan juga bahwa $40 \%$ mahasiswa di Oman dan 80\% mahasiswa di India menghabiskan waktunya untuk menggunakan internet tersebut untuk hal-hal yang berhubungan dengan kegiatan akademik (Datt \& Washington, 2015). Di Indonesia, 79,8\% mahasiswa menggunakan internet untuk mencari informasi, pertemanan dan hiburan (Panji, 2014).

$$
\text { Kondisi di atas hendaknya }
$$
mendorong tenaga pengajar (dosen) di Indonesia untuk memanfaatkan internet sebagai sumber belajar bagi mahasiswanya dan dirinya, pengembangan profesional, peningkatan belajar mandiri mahasiswa dan menambah wawasan, pergaulan, pengetahuan dan pengembangan karirnya (Darmansyah, 2010), dan memperoleh materi ajar yang autektik dan relevan yang dapat meningkatkan bahasa dan kebudayaan bahasa itu sendiri (Ngunyen, 2008). Lyashensko (2016) memberikan gagasan bahwa kondisi pedagogis tertentu harus diciptakan untuk menyukseskan penyebaran teknologi. Pendekatan partisipatif disarankan sebagai dasar kolaborasi antara dosen dan mahasiswa. Artinya, penyebaran teknologi perlu dikaitkan dengan keperluan pedagogis atau pendidikan. Adalah tugas seorang dosen untuk menggabungkan tekhnologi dengan pembelajaran agar mahasiswanya memiliki kemampuan akademis yang baik (Günaydin \& Karamete, 2016).
Pembelajaran berbasis multimedia merupakan produk pembelajaran yang memanfaatkan teknologi yang mampu meningkatkan hasil dan minat belajar mahasiswa. Mayer dan Moreno (2002) menyatakan bahwa multimedia mampu meningkatkan pemahaman peserta didik (mahasiswa). Mayer dalam beberapa bukunya menyebutkan bahwa "People learn better from words and pictures than from words alone". Artinya mahasiswa belajar lebih baik dengan menggabungkan teks dan gambar. Siskos dan Antoniou (2005) menambahkan bahwa sifat interaktif pembelajaran multimedia mampu meningkatkan minat mahasiswa. Selain itu, multimedia juga memberikan dorongan bagi mahasiswa dalam proses pembelajaran. Mereka juga berpendapat bahwa siwa/mahasiswa akan lebih perhatian dalam proses pembelajaran, ketika guru dan dosen menggunakan animasi dan narasi sebagai media petunjuk. Multimedia dapat merubah situasi dari having to learn into willing to learn (Liu, 2010). Jingjit (2015) juga menemukan bahwa multimedia efektif untuk meningkatkan penguasaan kosa kata murid sekolah dasar di Thailand.

Temuan serupa juga ditemukan di Indonesia. Dosen pengampu mata kuliah Listening di Jurusan Bahasa Inggris Universitas Negeri Padang (UNP) mendapatkan fakta bahwa dengan menggunakan multimedia hasil pembelajaran mahasiswa jauh lebih meningkat dibandingkan dengan media sebelumya, yaitu kaset dan tape recorder. Mahasiswa lebih bergairah dan antusias dalam proses belajar mengajar (Refnaldi, Ardi, \& Tiarina, 2010). Ilyas dan Mursid (2014) membuktikan bahwa bahan ajar berbasis multimedia mampu meningkatkan hasil belajar siswa. Penelitian Ampa (2015) di Universitas Muhammadiyah Makasar juga menunjukkan bahwa multimedia efektif dalam pembelajaran. Temuan di atas menjadi bukti bahwa multimedia dapat meningkatkan hasil dan minat belajar. 
Penelitian-penelitian di atas hanya terfokus kepada pengaruh multimedia terhadap hasil belajar dan minat mahasiswa.Belum ada penelitian yang membahas tentang praktikalitas multimedia berbentuk software pendidikan yang bisa diakses dengan mudah oleh mahasiswa. Hal ini penting untuk diteliti karena Brady dan Kennedy (2007) memberi peringatan bahwa software pendidikan yang tersedia tidak selalu kreatif dan inovatif. Software tersebut bisa saja menindas pendidikan. Artinya software tersebut hanya memberikan latihan-latihan seperti yang ada di buku. Selain itu Caftori dan Paprzycki dalam Brady dan Kennedy (2007) telah mengidentifikasi sejumlah paket software yang memiliki tujuan pendidikan yang baik tapi pada pelajar hanya menjadi pengalaman bermain games bukan pengalaman belajar yang sebenarnya. Ada juga ditemukan sofware yang menyebabkan perbedaan gender. Labor Komputer sepertinya menjadi "ruang" bagi pelajar lakilaki dibanding pelajar perempuan.

Salah satu pemanfaatan multimedia dalam pembelajaran adalah menjadikan multimedia interaktif sebagai media dalam materi ajar. Materi ajar yang merupakan "menu pokok" kurikulum (Graves dalam Ansyar, 2015) perlu dikembangkan agar sesuai dengan kebutuhan mahasiswa. Materi ajar berbasis multimedia interaktif yang dikembangkan perlu untuk diuji praktikalitasnya secara individu dan dalam kelompok kecil.

Oleh karena itu penelitian ini bertujuan untuk menemukan praktikalitas materi ajar Basic Grammar berbasis multimedia secara individu, dalam kelompok dan apakah terdapat perbedaan pendapat antara mahasiswa laki-laki dan mahasiswa perempuan terhadap praktikalitas materi ajar berbasi multimedia interaktif.

Materi ajar, sering juga diistilahkan dengan bahan ajar, bahan pengajaran, materi pelajaran, atau bahan pelajaran, adalah hal yang sangat penting di dalam menunjang terjadinya proses belajar, dan menempati kedudukan yang menentukan keberhasilan belajar mengajar untuk mencapai tujuan pembelajaran, dan menentukan kegiatankegiatan belajar mengajar (Hamalik, 2008). Senada dengan pernyataan diatas, Sanjaya (2008, hal. 141) menegaskan bahwa materi ajar meruapakan isi kurikulum yang harus dikuasai oleh siswa/mahasiswa dengan kompetensi dasar dalam rangka pencapaian standar kompetensi setiap mata pelajaran dalam satuan pendidikan tertentu. Pada prinsipnya materi ajar adalah konten kurikulum, dan merupakan tulang punggung atau "menu pokok" kurikulum (Graves dalam Ansyar, 2015). Konten kurikulum menjawab pertanyaan "Materi apa yang harus dipelajari, atau apa yang harus diajarkan kepada siswa agar tujuan pendidikan tercapai ?" (Ansyar, 2015, hal. 340). Dengan demikian dapat disimpulkan bahwa materi ajar merupakan alat untuk mencapai tujuan belajar mengajar.

Berkenaan dengan peranan materi ajar, Cunningsworth (1995) menyimpulkan bahwa ada beberapa peranan penting materi ajar dalam pembelajaran. Pertama, materi ajar berperan sebagai stimulus dalam proses belajar mengajar. Kedua, materi ajar berperan sebagai sebuah organisasi/susunan pembelajaran. Ketiga, materi ajar berperan sebagai suatu sumber kegiatan latihan dan interaksi komunikatif bagi siswa. Keempat, materi ajar berperan sebagai rujukan tatabahasa, kosa kata, pelafalan dan lain- lain. Kelima, materi ajar berperan sebagai sebuah silabus yang merefleksikan tujuan-tujuan belajar yang sudah ditetapkan. Terakhir, materi ajar berperan sebagai pendukung bagi guru yang kurang pengalaman yang ingin mencapai suatu kepercayaan diri dalam mengajar.

Bandono (2009) juga memberikan lima peranan dan manfaat materi ajar bagi pengajar atau dosen. Pertama, dengan adanya materi ajar yang tidak hanya berbentuk buku teks, pengajar tidak bergantung pada buku teks yang terkadang sulit diperoleh. Kedua, materi ajar memperkaya pengajar karena dikembangkan dengan berbagai referensi. Ketiga, materi ajar menambah khasanah dan pengetahuan pengajar dalam bidang ilmunya. Keempat, materi ajar membangun 
komunikasi efektif antara pembelajar dan pengajar karena materi ajar buatan pengajar membuat pembelajar lebih percaya kepadanya. Terakhir, materi ajar dirancang sesuai dengan tuntuan kurikulum.

Begitu pentingnya peranan materi ajar sehingga dosen benar-benar harus mempersiapkan materi ajar yang efektif. Materi ajar yang efektif adalah materi ajar yang tidak hanya menggunakan teks, akan tetapi juga menggunakan gambar, animasi, audio dan visual. Hal ini disebabkan karena mahasiswa akan belajar lebih baik dari perpaduan semua elemen, yang dikenal dengan multimedia (Mayer, 2005).

Banyak pendapat mengenai hakikat multimedia. Multimedia secara sederhana bermakna 'banyak media' atau 'kombinasi penggunaan media". Multimedia merupakan integrasi dari media berupa teks, grafik, video, animasi dan suara untuk menghadirkan dan menyampaikan informasi (Costello, Youngblood, \& Youngblood, 2012; Ivers \& Barron, 2010; Li \& Drew, 2004; Mayer R. E., 2001; Newby, Stepich, Lehman, \& Russell, 2000; Roblyer \& Doering, 2010; Simkins, Cole, Tavallin, \& Means, 2002; Smaldino, Russell, Heinich, \& Molenda, 2014; Solomon, 2011). Kata multimedia bisa digunakan untuk suatu paket komputer yang mencakup segmen-segmen video dan juga bisa digunakan untuk suatu pelajaran dengan banyak media dengan video sebagai salah satu unsurnya (Koumi, 2006).

Dalam definisi ini terkandung empat komponen penting multimedia. Pertama, harus ada komputer yang mengkoordinasikan apa yang dilihat dan didengar. Kedua, harus ada link yang menghubungkan pemakai dengan informasi. Ketiga, harus ada alat navigasi yang membantu pemakai menjelajah jaringan informasi yang saling terhubung. Keempat, multimedia menyediakan tempat kepada pemakai untuk mengumpulkan, memproses, dan mengkomunikasikan informasi dengan ide. Jika salah satu komponen tidak ada, bukan multimedia dalam arti luas namanya.

$$
\text { Tomlinson (2006) juga }
$$

mengemukakan prinsip-prinsip pemerolehan bahasa kedua yang relevan dengan pengembangan materi pembelajaran bahasa. Pertama, materi harus mencapai dampak (impact). Kedua, materi harus membuat mahasiswa merasa mudah. Ketiga, materi harus membantu mahasiswa mengembangkan rasa percaya diri. Keempat, apa yang diajarkan harus diterima mahasiswa sebagai sesuatu yang relevan dan berguna. Kelima, materi harus mensyaratkan dan memfasilitasi investasi diri mahasiswa. Keenam, mahasiswa harus siap memperoleh poin-poin yang diajarkan. Ketujuh, perhatian mahasiswa harus diarahkan pada fitur-fitur linguistik dari input yang diberikan. Kedelapan, materi harus menyediakan kesempatan bagi mahasiswa untuk menggunakan bahasa target untuk mencapai tujuan-tujuan komunikatif. Kesembilan, materi harus memperhatikan bahwa efek positif mahasiswaan biasanya datang belakangan. Kesepuluh, materi harus mempertimbangkan bahwa mahasiswa mempunyai gaya belajar yang berbeda-beda. Kesebelas, materi harus mempertimbangkan bahwa mahasiswa mempunyai sikap afektif yang berbeda-beda. Kedua belas, materi harus mengizinkan adanya periode diam (silent period) pada awal pembelajaran. Ketiga belas, materi harus memaksimalkan potensi belajar dengan mendorong keterlibatan intelektual, estetika, dan emosional yang menstimulasi baik kegiatan otak kiri maupun otak kanan. Keempat belas, materi seharusnya tidak banyak tergantung pada latihan-latihan terkontrol. Terakhir, materi harus menyediakan kesempatan bagi umpan balik dampak (outcome feedback).

\section{METODE}

Sesuai dengan tujuan penelitian untuk menemukan praktikalitas materi ajar berbasis multimedia, maka penelitian ini termasuk penelitian kuantitatif. Populasi penelitian ini adalah mahasiswa jurusan Bahasa dan Sastra Inggris yang sedang mempelajari tata bahasa dengan menggunakan materi ajar Basic Grammar berbasis multimedia yang dikembangkan oleh Yuli Tiarina dan dapat 
diakses melalui http://thetiarina.com/etiarina/ (Screeshot E-Basic English Grammar terlampir). Sampel penelitian menggunakan purposive sampling teknik. Untuk melihat praktikalitas dari individu, peneliti melibatkan 3 orang mahasiswa. Mahasiswa yang dipilih adalah mahasiswa yang memiliki nilai terendah, sedang dan tertinggi berdasarkan ujian diagnostik mahasiswa. Sementra itu untuk kelompok kecil, penelitian ini melibatkan 27 mahasiswa, yaitu terdiri dari 11 mahasiswa laki-laki dan 16 mahasiswa perempuan. Untuk mengumpulkan data digunakan angket skala likert dengan rentang 1-4 dan lembar observasi. Indikatornya adalah kualitas desain pembelajaran, kualitas disain tampilan komunikasi, kemudahan penggunaan materi ajar dan kemudahan organisasi materi ajar. Untuk menguji validitas angket ini, peneliti menggunakan validitas konten dengan menggunakan penilaian pakar multimedia. Reliabitas instrumen ini menggunakan Alpha Cronbach karena data berbentuk skala. Hasil reliabilitas instrumen ini tinggi yaitu 0,948 untuk uji individu dan 0,903 untuk uji kelompok kecil. Data dikumpulkan dengan teknik observasi. Sebelum observasi dilakukan, peneliti melakukan pendataan nama mahasiswa untuk dibuatkan akun supaya dapat mengakses website materi ajar. Skor diperoleh dari skor mahasiswa yang berskala 1-4. Bobot 1 untuk tidak baik/tidak bisa dipahami, bobot 2 untuk kurang baik/kurang bisa dipahami , bobot 3 untuk baik/bisa dipahami dan bobot 4 untuk sangat baik/sangat bisa dipahami. Skor akhir diperoleh dengan mengadaptasi kriteria penilaian oleh Direktorat Pembinaan SMA 2010.

\section{HASIL DAN PEMBAHASAN}

\section{Praktikalitas Materi ajar Basic Grammar Berbasis Multimedia Interaktif secara Individu}

Berikut ini adalah hasil dari uji praktikalitas draft kedua materi ajar Basic Grammar berbasis multimedia interaktif.

Tabel 1 Skor Penilaian Draft Awal Materi Ajar Basic Grammar pada Uji Individu Tentang Kualitas Desain

\begin{tabular}{llll}
\hline No. & \multicolumn{1}{c}{ Indikator Penilaian } & $\begin{array}{c}\text { Rata- } \\
\text { rata }\end{array}$ & \multicolumn{1}{c}{ Kriteria } \\
\hline 1. & Tampilan Judul & 75,00 & Baik \\
2. & Kejelasan SK-KD & 91,67 & Sangat Baik \\
3. & Kesesuaian Tujuan Pembelajaran dengan SK-KD & 83,33 & Baik \\
4. & Kesesuaian Materi dengan tujuan pembelajaran & 91,67 & Sangat Baik \\
5. & Ketersediaan Contoh Soal & 83,33 & Baik \\
6. & Ketersediaan Latihan/Tugas & 83,33 & Baik \\
7. & Ketersediaan Identitas Penyusun & 83,33 & Baik \\
8. & Ketersediaan Referensi & 91,67 & Sangat Baik \\
\hline Total & & 85,47 & Baik
\end{tabular}


Tabel 2 Skor Penilaian Draft Awal Materi Ajar Basic Grammar pada Uji Individu Tentang Kualitas Tampilan Komunikasi Visual

\begin{tabular}{llll}
\hline No. & & Indikator Penilaian & \multicolumn{2}{l}{ Rata-rata } & \\
\hline 1. & Navigasi & 75,00 & Baik \\
2. & Huruf & 83,33 & Baik \\
3. & Film, Suara, gambar, animasi & 83,33 & Baik \\
4. & Komposisi warna & 91,67 & Sangat Baik \\
5. & Animasi & 83,33 & Baik \\
6. & Layout & 83,33 & Baik \\
\hline Total & & 83,33 & Baik \\
\hline
\end{tabular}

Dua tabel diatas menunjukkan bahwa draft kedua materi ajar tergolong baik. Ada 4 aspek yang sangat baik dan 10 aspek tergolong baik.

Ada dua aspek yang mendapatkan nilai 75. Artinya ke 3 mahasiswa (individu) memberikan nilai yang sama. Walaupun tergolong baik, namun nilai ini lebih rendah dibanding dengan nilai aspek yang lain. Pertama, tampilan judul dinilai baik oleh individu. Ketika melakukan uji individu ini, peneliti menanyakan kepada individu mengapa tampilan judul mendapatkan skor 3 (baik). Menurut mereka tampilan judul terlalu sederhana; tidak ada gambar-gambar. Hal ini merupakan poin pertama yang menjadi pertimbangan untuk revisi draft materi ajar. Kedua, ketiga mahasiswa memberi angka tiga (baik) untuk navigasi. Sewaktu observasi dilakukan mahasiswa bingung ketika mereka diminta untuk membuka time to watch dan 8 tahap lainnya. Hal ini disebabkan 9 tahapan tersebut ada dalam satu lesson. Mereka harus membuka lesson; baca tujuan pembelajaran, klik time to watch. Artinya mereka harus membuka tahapan secara berurutan. Dari kebingunan navigasi tersebut, peneliti medapatkan poin kedua yang mesti di revisi, yaitu membuat setiap tahapan di luar lesson. Artinya, pengguna bisa dapat melihat langsung enam tahapan sehingga mereka bebas dan mudah memilih enam tahapan dari menu utama. Navigasi lebih sederhana dan mudah dipahami.

\section{Praktikalitas Materi ajar Basic Grammar Berbasis Multimedia Interaktif Dalam Kelompok Kecil}

Berikut ini hasil uji coba praktikalitas kelompok kecil yang berjumlah 27 mahasiswa. 
Tiarina, Syarif, Jufrizal, \& Rozimela, Praktikalitas Materi Ajar Basic Englis Grammar ...

Tabel 3. Skor Penilaian Draft Awal Materi Ajar Basic Grammar pada Uji Kelompok Kecil Tentang Kualitas Desain Pembelajaran

\begin{tabular}{llll}
\hline No. & Indikator Penilaian & Rata-rata & Kriteria \\
\hline 1. & Tampilan Judul & 78,70 & Baik \\
2. & Kejelasan SK-KD & 83,33 & Baik \\
3. & Kesesuaian Tujuan Pembelajaran dengan SK-KD & 86,11 & Baik \\
4. & Kesesuaian Materi dengan tujuan pembelajaran & 87,96 & Baik \\
5. & Ketersediaan Contoh Soal & 82,41 & Baik \\
6. & Ketersediaan Latihan/Tugas & 89,81 & Baik \\
7. & Ketersediaan Identitas Penyusun & 83,33 & Baik \\
8. & Ketersediaan Referensi & 82,41 & Baik \\
\hline Total & & 84,26 & Baik \\
\hline
\end{tabular}

Tabel 4. Skor Penilaian Draft Awal Materi Ajar Basic Grammar pada Uji Kelompok Kecil Tentang Tampilan Komunikasi Visual

\begin{tabular}{llll}
\hline No. & Indikator Penilaian & Rata-rata & Kriteria \\
\hline 1. & Navigasi & 87,04 & Baik \\
2. & Typografi/Huruf & 89,81 & Baik \\
3. & Film & 91,67 & Sangat Baik \\
4. & Gambar & 89,81 & Baik \\
5. & Komposisi warna & 87,96 & Baik \\
6. & Animasi & 87,04 & Baik \\
7. & Layout & 85,85 & Baik \\
8. & Background/Latar belakang & 85,18 & Baik \\
\hline Total & & 87,85 & Baik \\
\hline
\end{tabular}

Dua tabel di atas menunjukkan bahwa materi ajar dinilai baik oleh kelompok mahasiswa. Nilai tampilan komunikasi visul meningkat dibanding dengan penilaian individu. Ini berarti bahwa revisi warna dan navigasi membuat materi ajar ini lebih baik. Kemudian, ada peningkatan penilaian untuk aspek tampilan judul dan navigasi. Kenaikan 
penilainnya dibandingkan draft awal adalah 4,93\% untuk tampilan judul dan 12,04\% untuk navigasi. Dalam uji coba praktikalitas pertanyaan uji praktikalitas dikembangkan menjadi kemudahan penggunaan materi ajar dan kemudahan organisasi materi ajar. Hasil penilaian kelompok dapat dillhat dalam tabel berikut ini.

Tabel 5. Skor Penilaian Draft Awal Materi Ajar Basic Grammar pada Uji Kelompok Kecil Tentang Kemudahan penggunaan Materi Ajar

\begin{tabular}{|c|c|c|c|}
\hline No. & Indikator Penilaian & $\begin{array}{c}\text { Rata- } \\
\text { rata }\end{array}$ & Kriteria \\
\hline 1. & $\begin{array}{l}\text { Materi ajar ini memberikan kemudahan untuk mempelajari Basic } \\
\text { Grammar dimana saja dan kapan saja. }\end{array}$ & 87,70 & Setuju \\
\hline 2. & $\begin{array}{l}\text { Materi ajar ini memberikan kemudahan untuk mempelajari Basic } \\
\text { Grammar kapan saja. }\end{array}$ & 86,11 & Setuju \\
\hline 3. & Materi ajar ini dapat meningkatkan penguasaan gramatika saya. & 75,93 & Setuju \\
\hline 4. & $\begin{array}{l}\text { Materi ajar ini memberikan kemudahan untuk mengerjakan } \\
\text { latihan/tugas Basic Grammar dimana saja dan kapan saja. }\end{array}$ & 86,11 & Setuju \\
\hline 5. & $\begin{array}{l}\text { Materi ajar ini memberikan kemudahan untuk mengerjakan } \\
\text { latihan/tugas Basic Grammar dimana saja. }\end{array}$ & 87,04 & Setuju \\
\hline 6. & Petunjuk materi ajar ini mudah dipahami. & 77,78 & Setuju \\
\hline 7. & Susunan materi ajar ini mudah dipahami. & 77,78 & Setuju \\
\hline 8. & Isi materi ajar ini mudah dipahami. & 77,78 & Setuju \\
\hline 9. & Materi ajar ini menyenangkan. & 83,33 & Setuju \\
\hline 10. & Materi ajar ini relevan. & 80,56 & Setuju \\
\hline 11. & Materi ajar ini berguna. & 87,96 & Setuju \\
\hline 12. & $\begin{array}{l}\text { Materi ajar ini membantu meningkatkan keterampilan mendengar } \\
\text { saya. }\end{array}$ & 86,11 & Setuju \\
\hline 13. & $\begin{array}{l}\text { Materi ajar ini membantu meningkatkan keterampilan berbicara } \\
\text { saya. }\end{array}$ & 71,30 & Setuju \\
\hline 14. & $\begin{array}{l}\text { Materi ajar ini membantu meningkatkan keterampilan membaca } \\
\text { saya. }\end{array}$ & 84,26 & Setuju \\
\hline 15. & Materi ajar ini membantu meningkatkan keterampilan menulis. & 77,78 & Setuju \\
\hline 16. & Materi ajar ini memberi peluang bagi saya untuk belajar mandiri. & 87,04 & Setuju \\
\hline 17. & Materi ajar ini memudahkan saya untuk beriteraksi dengan dosen. & 76,85 & Setuju \\
\hline 18. & $\begin{array}{l}\text { Materi ajar ini memudahkan saya untuk beriteraksi dengan sesama } \\
\text { teman. }\end{array}$ & 78,70 & Setuju \\
\hline Total & & 81,64 & Setuju \\
\hline
\end{tabular}

Berdasarkan tabel di atas, mahasiswa setuju bahwa materi ajar ini tergolong dapat digunakan dengan mudah. Dari nilai penilaian yang diberikan dapat dinyatakan bahwa materi ajar yang menyenangkan ini berguna bagi mereka karena mereka dapat 
mempelajari tata bahasa di mana saja dan kapan saja. Materi ajar ini dapat memberikan kemudahan untuk mengerjakan latihan di mana saja dan kapan saja. Materi ajar ini memberi peluang belajar secara mandiri. Materi ajar ini dapat meningkatkan keterampilan mendengar dan membaca mahasiswa.

Memang itulah kelebihan materi ajar yang berbasis multimedia interaktif yang dikemas dalam bentuk on line. Artinya, materi ini dapat dipelajari dimana saja dan kapan saja. Meningkatnya keterampilan mendengar dan membaca mahasiswa disebabkan karena mereka terlatih untuk mendengar dan membaca film, cerita pendek, lagu dan puisi. Belum meningkatnya keterampilan berbicara dan menulis mahasiswa disebabkan karena masih ada mahasiswa yang belum mengerjakan time for action padahal pada tahap itu mereka dilatih untuk berbicara dan menulis yaitu mereka ditugasi untuk membuat cerita, menampilkan cerita di Youtube, membuat puisi dan menampilkan di Youtube.

Pada uji kelompok kecil ini juga ditemukan penilaian mahasiswa terhadap kemudahan organisasi materi ajar. Hasil penilaian mahasiswa tersebut dapat dilihat dari tabel di bawah ini.

Tabel 6. Skor Penilaian Draft Awal Materi Ajar Basic Grammar pada Uji Kelompok Kecil Tentang Kemudahan Organisasi Materi Ajar

\begin{tabular}{|c|c|c|c|c|c|c|c|c|}
\hline \multirow[t]{2}{*}{ No. } & \multirow{2}{*}{$\begin{array}{l}\text { Indikator } \\
\text { Penilaian }\end{array}$} & \multicolumn{4}{|c|}{ Skor Responden } & \multirow{2}{*}{$\begin{array}{c}\text { Jumlah } \\
\text { Skor }\end{array}$} & \multirow[t]{2}{*}{ Rata-rata } & \multirow[t]{2}{*}{ Kriteria } \\
\hline & & 1 & 2 & 3 & 4 & & & \\
\hline 1. & $\begin{array}{l}\text { RPS (Rancangan } \\
\text { Perkuliahan } \\
\text { Persemester) }\end{array}$ & & 5 & 19 & 3 & 79 & 73,15 & Dapat dipahami \\
\hline 2. & Preface & & 3 & 20 & 4 & 82 & 75,93 & Dapat dipahami \\
\hline 3. & Time to Watch & & 2 & 14 & 11 & 90 & 83,33 & Dapat dipahami \\
\hline 4. & Time to Chat & & 5 & 19 & 3 & 79 & 73,15 & Dapat dipahami \\
\hline 5. & Time to Focus & & 1 & 16 & 10 & 90 & 83,33 & Dapat dipahami \\
\hline 6. & Time to Practice & & & 15 & 12 & 93 & 86,11 & Dapat dipahami \\
\hline 7. & Time for Fun & & & 6 & 21 & 102 & 94,44 & $\begin{array}{l}\text { Sangat Dapat } \\
\text { dipahami }\end{array}$ \\
\hline 8. & Time for Tube & & 3 & 16 & 8 & 86 & 79,62 & Dapat dipahami \\
\hline 9. & Time for Action & 1 & 5 & 15 & 6 & 80 & 74,07 & Dapat dipahami \\
\hline \multicolumn{2}{|c|}{ Total Skor } & & & & & $781 / 972$ & 80,35 & Dapat dipahami \\
\hline
\end{tabular}

Dari tabel di atas dapat bahwa organisasi materi ajar dapat dipahami. Aspek yang sangat dapat dipahami adalah Time for Fun. Hal ini menunjukkan bahwa mahasiswa sangat menyukai adanya permainan dalam materi tentang kemudahan penggunanaa materi ajar maka tampak hubungannya bahwa ajar. Jika dilihat lagi penilaian mahasiswa salah satu penyebab materi ajar ini 
menyenangkan adalah karena adanya permainan.

\section{SIMPULAN}

Materi ajar Basic English Grammar berbasis multimedia interaktif yang bersifat praktis ini membuat mahasiswa menjadi senang dan mau untuk belajar. Penggunaan games dan penyampaian materi secara daring terbukti membuat mahasiswa dapat belajar kapan saja dan dimana saja. Materi ajar ini memberikan kemudahan bagi mahasiswa untuk mengerjakan latihan kapan dan dimana saja. Materi ajar ini relevan dan berguna bagi mahasiswa. materi ajar ini meningkat keterampilan bahasa. Materi ajar ini memberi peluang agar mahasiswa dapat belajar mandiri dengan tetap dapat berinteraksi dengan dosen ataupun temannya. Implikasi dari penelitian ini adalah materi ajar ini dapat digunakan sebagai materi untuk model pembelajaran blended learning.

\section{DAFTAR RUJUKAN}

Ampa, A. T. (2015). The implementation of interactive multimedia learning materials in teaching listening skills. English Language Teaching (Online), Vol. $\quad 8, \quad$ No. 2, (bttp:/ / dx.doi.org/10.5539/elt.v8n12p 56), 56-62.

Ansyar, M. (2015). Kurikulum: Hakikat,fondasi, desain \& pengembangan. Jakarta: Kencana.

Bandono. (2009, Februari 02). Retrieved Maret 16, 2017, from http://bandono.web.id/2009/04/ 02/pengembangan-bahanajar//htm.

Brady, L., \& Kennedy, K. (2007). Curriculum construction. French NSW: Pearson Prentice Hall.

Costello, V., Youngblood, S. A., \& Youngblood, N. E. (2012). multimedia foundations. Oxford: Focal Press.

Cunningsworth, A. (1995). Choosing your coursebook. Oxford: Heinemann.
Darmansyah. (2010). Pembelajaran berbasis web: Teori, konsep dan aplikasi. Padang: UNP Press.

Datt, P., \& Washington, A. (2015). Influence of internet on social and cultural values: A comparative study of youth in Oman and India. International Journal of Education and Research (Online), 3(11). (bttp:/ / wnw.ijern.com), 359-372.

Günaydin, S., \& Karamete, A. (2016). Material development to raise awareness of using smart boards: An example of design and developmental research. European Journal of Contemporary Education, 15 (1), 114-122.

Hamalik, O. (2008). Proses belajar mengajar. Bandung: Bumi Aksara.

Ilyas, \& Mursid, R. (2014). Pengembangan bahan ajar berbasis multimedia interaktif pada pembelajaran Keterampilan Komputer dan Pengelolaan Informasi. Portal Garuda.(online) portal garuda.org/article.php.

Ivers, K. S., \& Barron, A. E. (2010). Multimedia projects in education: Designing, producing and assesing. California: ABC-CLIO, LLC.

Jingjit, M. (2015). The effects of multimedia learning on Thai primary pupils' achievement in size and depth of vocabulary knowledge. Journal of Education and Practice (Online), 6(32), (bttp:// wnw.iiste.org), 72-81.

Koumi, J. (2006). Designing video and multimedia for open and flexible Learning. London: Routledge Taylor \& Francis Group.

Li, Z. (2012). Application of online multimedia courseware in college English teaching based on constructivism theory. English Language Teaching Journal (online), 5(3), (bttp:/ / mww.ccsenet.org/elt), 197201.

Li, Z.-N., \& Drew, M. S. (2004). Fundamentals of multimedia. Australia: Prentice Hall. 
Liu, J. (2010). An experimental study on the effectiveness of multimedia in college English teaching. English Teaching Journal (Online), 3(1), (bttp:/ / wown.ccsenet.org/elt), 191-194.

Lyashensko, M. (2016). Implementation of web-based technologies into teaching and learning practices in the university. International Journal of Information and Education Technology (Online), 6(3), (bttp://mmw.ijet.org), 243-246.

Mayer, R. E. (2001). Multimedia Learning. New York: Cambridge University Press.

Mayer, R., \& Moreno, R. (2002). Aids to computer-based multimedia Learning. Learning and Instruction, No.12, 107-119.

Newby, T. J., Stepich, D. A., Lehman, J. D., \& Russell, J. D. (2000). Instructional for teaching and learning. New Jersey: Prentice Hall.

Ngunyen, L. V. (2008). Technologyenhanced EFL syllabus design and materials development. English Language Teaching (Online), 1(2), (bttp:/ / wnw.ccsenet.org/journal.btml), 135-142.

Panji, A. (2014, February 19). About U: Kompas.Com. Retrieved August 25, 2017, from Kompas.Com Web Site: http://tekno.kompas.com/read

Refnaldi, Ardi, H., \& Tiarina, Y. (2010). Pengembangan materi ajar Listening 1 berbasis multimedia. Padang: Tidak Dipublikasikan.

Roblyer, M. D., \& Doering, A. (2010). Integrating educational technology into teaching (5th Ed). Boston: Allyn dan Bacon.

Sanjaya, W. (2008). Perencanaa dan Desain Sistem Pembelajaran. Jakarta: Prenada Media Group.

Simkins, M., Cole, K., Tavallin, F., \& Means, B. (2002). Increasing Students Learning through Multimedia Projects.

Siskos, A., \& Antoniou, P. (2005). Effects of multimedia Computer-Assisted Instruction (MCAI) on academic achievement in physical education of Greek primary students. Interactive Educational Multimedia (Online), No. 10, (bttp:// wnw.ub.edu/multimedia/iem), 61-77.

Smaldino, S. E., Russell, J. D., Heinich, R., \& Molenda, M. (2014). Instructional Media and Teachnology for Learning. Ed.10th. New Jersey: Prentice Hall.

Solomon, A. W. (2011). Introduction to multimedia. Columbus: Glencoe/Mc. Grow Hill.

Tomlinson, B. (2006). Materials development in language teaching. In B. Tomlinson, Materials Development in Language Teaching (pp. 1-24). Cambridge: Cambridge University Press. 